\title{
Histoquímica de la corteza de cinco angiospermas de una selva baja de Oaxaca
}

\author{
Claudia Paredes ${ }^{1}$ \\ Alejandra Quintanar ${ }^{1}$ \\ Salvador Acosta ${ }^{2}$ \\ Gabriel Orozco ${ }^{1}$ \\ Carmen de la Paz Pérez ${ }^{1}$ \\ Alfonso Torre-Blanco ${ }^{3}$
}

\begin{abstract}
RESUMEN
Se estudiaron algunas características anatómicas e histoquímicas de la corteza de cinco angiospermas: Cercidium plurifoliolatum Micheli, Ipomea pauciflora Martens \& Galeotti, Jatropha andrieuxii Muell. Arg., Lysiloma divaricata (Jacq.) MacBride, Ziziphus amole (Sessé \& Mociño) M.C. Johnston, provenientes de una selva baja de Oaxaca. Se obtuvieron porciones de corteza que incluyeran albura y se elaboraron cortes transversales, tangenciales y radiales. Para los caracteres anatómicos se usó la terminología propuesta por Trokenbrodt (1990) y se localizaron: lípidos, pectinas, pectatos de calcio, ligninas, polifenoles, hemicelulosas y celulosa. En cuanto a los radios se observan dos grupos: en uno se forman abanicos que después constituyen bandas tangenciales; en el otro los radios son interrumpidos por alguna estructura tangencial como son: bandas de parénquima axial, fibras o grupos de esclereidas. Resalta el arreglo radial del parénquima axial en Jatropha. En la localización de pectatos de calcio, resaltó una reacción intensa en la mayoría de las células de los cinco ejemplares. Los contenidos celulares muestran una diversidad en su composición resaltando los canales de Jatropha que presentan reacciones intensas a polifenoles, pectatos de calcio y lípidos. El resto de las reacciones muestran un proceso de lignificación del parénquima axial hacia el exterior. Hay presencia importante de cristales en los cinco ejemplares. Se presentan los resultados, en detalle, de las diferencias histoquímicas de la corteza de estas plantas.
\end{abstract}

PALABRAS CLAVE:

Histoquímica, anatomía, corteza, selva baja caducifolia, Oaxaca.

\begin{abstract}
Anatomical and histochemical features of the bark of Cercidium plurifoliolatum Micheli, Ipomea pauciflora Martens \& Galeotti, Jatropha andrieuxii Muell. Arg., Lysiloma divaricata (Jacq.) MacBride, Ziziphus amole (Sessé \& Mociño) M.C. Johnston from a seasonal dry forest of Oaxaca were analyzed. Transverse, tangential and radial sections were obtained from pieces of bark that included sapwood. The terminology of Trokenbrodt (1990) for anatomical characters was used. Lipids, pectins, calcium pectates, lignin and polyphenols were visualized by histochemical reactions. Two types of rays were observed: the first type form fanlike structures that become tangential bands; in the other type, rays are interrupted by small tangential structures such as axial parenchyma, fibers or groups of sclereids. It is noteworthy the radial array of axial parenchyma in Jatropha. Most cells of all species showed a strong reaction to calcium pectates. The composition of cellular contents shows a great diversity; noteworthy is the strong reaction to polyphenols, calcium pectates and oils in Jatropha's secretory canals. It is evident a general pattern of lignification from the axial parenchyma outwards. The presence of abundant crystals was observed in the five species analyzed. Differences in the histchemical features of the bark between the species are discussed.
\end{abstract}

KEY WORDS:

Histochemistry, anatomy, bark, seasonal dry forest, Oaxaca. 


\section{INTRODUCCIÓN}

La corteza y el floema secundario han sido descritos y discutidos en términos de sus tipos y arreglos celulares (Esau, 1972; Fahn, 1990). Trokenbrodt (1990) y Junikka (1994) han revisado la nomenclatura de este tejido y propuesto lineamientos para su descripción. Otros autores como Furuno (1990) proponen diferentes tipos de clasificación de acuerdo con los radios, fibras floemáticas y esclereidas en 55 especies de clima templado y de montaña. Alfonso y Richter (1991); Archer y van Wyk (1993); Trockenbrodt (1994), Carlquist et al. (1994) y Potgieter y van Wyk (1994) destacan por sus estudios anatómicos comparativos de sistemática. Malan y Van Wyk (1993) estudian la relación que tienen las propiedades de ruptura y la selección de su consumo por los elefantes. Angeles y León (1997) estudian el desarrollo del floema secundario de especies de la familia Vitaceae. Jorge et al. (2000) estudian la variación en la longitud de las fibras de la corteza de Eucalyptus globosus. Es interesante notar que solamente Nunes et al. (1996) estudian la anatomía y química del floema secundario de Pinus pinaster, encontrando que al abalizar sus cenizas, el $11.4 \%$ están relacionados con extractivos y de allí el $4.5 \%$ corresponden a taninos mientras que otros porcentajes menores a compuestos de azúcares. En este panorama no se registran estudios histoquímicos de este tejido, salvo en xilema secundario de algunas especies mexicanas (Quintanar et al., 1997 y Rivera et al., 1999).

Las especies estudiadas provienen de la parte alta de la Cuenca del Río Tehuantepec, Municipio de Totolapan, donde predomina el bosque tropical caducifolio (Acosta, 1992) o selva baja caducifolia, que se desarrolla sobre un suelo pedregoso. La temperatura media anual es de $26^{\circ} \mathrm{C}$ y la precipitación media anual de $460 \mathrm{~mm}$. Las especies que se estudiaron fueron: Cercidium plurifoliolatum Micheli (Leguminosae), Ipomea pauciflora Martens \& Galeotti (Convolvulacea), Jatropha andrieuxii Muell. Arg. (Euphorbiaceae), Lysiloma divaricata (Jacq.) MacBride (Leguminosae) y Ziziphus amole (Sessé \& Mociño) M. C. Johnston (Rhamnaceae). A excepción de Jatropha, las demás son empleadas para leña y ocasionalmente para postería. En esta cuenca, el sustento de los pobladores se basa en la explotación de la piedra de río, lo que ha ocasionado que las faldas y lomas comiencen a ser explotadas y por tanto se prevea una destrucción continua de la vegetación.

Los estudios histoquímicos proporcionan información muy valiosa, pues ayudan a entender la calidad de las paredes celulares, el tipo de contenidos celulares y aspectos de las estrategias de protección de cada especie. Asimismo, pueden ayudar a diversificar y dar alternativas nuevas de uso.

\section{OBJETIVO}

El objetivo de este trabajo se centró en contribuir al conocimiento histoquímico y anatómico de las cortezas de 5 especies de una selva baja caducifolia de Oaxaca.

\section{METODOLOGÍA}

El material estudiado proviene de árboles de las siguientes especies: $C$. plurifoliolatum (Leguminosae), I. pauciflora (Convolvulacea), J. andrieuxii (Euphorbia-ceae), L. divaricata (Leguminosae), Z. amole (Rhamnaceae), cuyos números de registro son: UAMIZM159, M167, M153, M152, M151 respectivamente. Los ejemplares de herbario se encuentran depositados en el Herbario del CIIDIR-IPN, Unidad-Oaxaca. 
Para cada especie se estudiaron dos ejemplares. Las muestras de corteza se obtuvieron cortando, a una altura de 1.30 $\mathrm{m}$, una pequeña porción del fuste, así como rodajas de ramas primarias, ambas con xilema secundario, que se fijaron inmediatamente en formol-alcohol-ácido acético-agua (FAA). Para C. plurifoliolatum e I. pauciflora sólo se estudiaron las cortezas de los fustes; para J. Andrieuxii, las ramas (arbusto) y para las otras dos se estudiaron fuste y rama. Las cortezas provenientes tanto de fuste como de rama, fueron seccionadas en pequeños cubos $(1.5 \times 1.5 \mathrm{~cm})$ incluyendo una porción de albura, con el fin de asegurar la presencia del cambium vascular. Las cortezas de Jatropha e Ipomea son muy deleznables, por lo que fue necesaria su inclusión en polietilenglicol 300-1500. El resto de las cortezas se cortaron sin hacer ningún ablandamiento o inclusión previa. Se obtuvieron cortes transversales, tangenciales y radiales, que se almacenaron en cajas de petri con FAA. Antes de cada tinción, los cortes se lavaron para eliminar el fijador. Se ensayaron cinco reacciones histoquímicas: el Azul de Toluidina-O se usó para teñir diferencialmente celulosa (azul), hemicelulosas (morado, azul lila, rosa-violeta) y lignina (azul turquesa). Para celulosa (azul a violeta) o lignina (amarillo a naranja) se siguió el método de Zinc-Cloro-lodo (ZnCII), aunque pueden presentarse carbohidratos de color violáceo en el lumen de las células. Para la detección de lípidos se uso Sudán III. El método ácido tánico-cloruro férrico se utilizó para observar pectatos de calcio (negro a azul oscuro). Los componentes fenólicos fueron teñidos específicamente por el método de vainillina (Johansen, 1940; Jensen, 1962; Krishnamurty, 1988).

Se tomaron fotografías de las diferentes reacciones de los tejidos; la intensidad de las reacciones se ponderó usando el símbolo (+). En este punto se designó como: + = escasa; ++ = mediana; $+++=$ intensa. También se elaboraron preparaciones fijas para realizar las siguientes cuantificaciones: longitud, diámetro y grosor de la pared celular de las fibras, altura y anchura del parénquima radial, ajustando los valores de las medias a un error $<0.05$.

\section{RESULTADOS}

En la tabla 1 se presentan los valores obtenidos de las cuantificaciones mencionadas (mínimos y máximos dentro del paréntesis y la media fuera de éste). En la tabla 2 se presenta un resumen de la intensidad de las reacciones obtenidas. Se presenta también una breve descripción de la anatomía de floema secundario y corteza. La terminología empleada es la propuesta por Trockenbrodt (1990).

Tabla 1. Comparación de dimensiones de fibras y radios $(\mu \mathrm{m})$

\begin{tabular}{lccccc}
\hline & LONGITUD & DIÁMETRO & GROSOR DE LA & ALTURA DE & ANCHURA \\
& DE FIBRA & DE FIBRA & PARED DE LA FIBRA & RADIO & DE RADIO \\
\hline Cercidium & 881 & 16 & 5.4 & 354 & 90 \\
& $(713-1312)$ & $(10-20)$ & $(4-8)$ & $(120-675)$ & $(38-172)$ \\
\hline Ipomea & 223 & 23.4 & 4 & 1242 & 275 \\
& $(164-320)$ & $(14-32)$ & $(3-5)$ & $(1087-1762)$ & $(172-300)$ \\
\hline Jatropha & 578 & 13 & 6.5 & 384 & 56 \\
& $(472-675)$ & $(10-14)$ & $(4-12)$ & $(270-502)$ & $(45-75)$ \\
\hline Lysiloma & 678 & 16 & 4 & 157 & 19 \\
& $(592-758)$ & $(14-20)$ & $(2-6)$ & $(135-188)$ & $(15-23)$ \\
\hline Ziziphus & 508 & 13 & 6.5 & 233 & 50 \\
& $(472-675)$ & $(10-14)$ & $(4-10)$ & $(158-315)$ & $(30-68)$ \\
\hline
\end{tabular}


Tabla 2. Comparación de las intensidades observadas para diferentes características

\begin{tabular}{|c|c|c|c|c|c|}
\hline ESPECIE & $\begin{array}{l}\text { AZUL DE } \\
\text { TOLUIDINA }\end{array}$ & VAINILLINA & $\begin{array}{c}\text { ÁCIDO } \\
\text { TÁNICO- } \\
\text { CLORURO- } \\
\text { FÉRRICO }\end{array}$ & $\begin{array}{l}\text { ZINC- } \\
\text { CLORO- } \\
\text { IODO }\end{array}$ & SUDÁN III \\
\hline \multicolumn{6}{|c|}{ Cercidium } \\
\hline $\begin{array}{l}\text { Parénquima } \\
\text { axial y radial }\end{array}$ & $\begin{array}{l}\text { ramas lila }+++ \\
\text { fuste turquesa } \\
++\end{array}$ & $\begin{array}{l}\text { peridermis } \\
++\end{array}$ & +++ & & $\begin{array}{l}\text { parénquima } \\
\text { axial ++ } \\
\text { peridermis +++ }\end{array}$ \\
\hline $\begin{array}{l}\text { Fibras y } \\
\text { esclereidas }\end{array}$ & turquesa +++ & ++ & +++ & & \\
\hline $\begin{array}{l}\text { Contenidos } \\
\text { celulares }\end{array}$ & & & +++ & + & \\
\hline \multicolumn{6}{|c|}{ Ipomea } \\
\hline $\begin{array}{l}\text { Parénquima } \\
\text { axial y radial }\end{array}$ & lila +++ & & +++ & & \\
\hline $\begin{array}{l}\text { Fibras, } \\
\text { esclereidas y } \\
\text { epidermis }\end{array}$ & $\begin{array}{l}\text { turquesa } \\
+++\end{array}$ & & ++ & & $\begin{array}{l}\text { epidermis + } \\
\text { córtex + }\end{array}$ \\
\hline $\begin{array}{l}\text { Contenidos } \\
\text { celulares }\end{array}$ & ++ & $\begin{array}{l}\text { parénquima ++ } \\
\text { córtex ++ }\end{array}$ & +++ & + & \\
\hline \multicolumn{6}{|c|}{ Jatropha } \\
\hline $\begin{array}{l}\text { Parénquima } \\
\text { axial y radial }\end{array}$ & lila ++ & & +++ & + & \\
\hline $\begin{array}{l}\text { Fibras y } \\
\text { esclereidas }\end{array}$ & turquesa +++ & & +++ & & \\
\hline $\begin{array}{l}\text { Contenidos } \\
\text { celulares }\end{array}$ & $\begin{array}{l}\text { canales } \\
\text { turquesa +++ }\end{array}$ & $\begin{array}{l}\text { canales } \\
\text { castaño ++ }\end{array}$ & $\begin{array}{l}\text { canales } \\
\text { negro +++ }\end{array}$ & & $\begin{array}{l}\text { canales y córtex } \\
++\end{array}$ \\
\hline \multicolumn{6}{|c|}{ Lysiloma } \\
\hline $\begin{array}{l}\text { Parénquima } \\
\text { axial y radial }\end{array}$ & $\begin{array}{l}\text { ramas lila }+++ \\
\text { fuste turquesa } \\
+++\end{array}$ & & ++ & & \\
\hline $\begin{array}{l}\text { Fibras y } \\
\text { esclereidas }\end{array}$ & +++ & ++ & + & & \\
\hline $\begin{array}{l}\text { Contenido } \\
\text { celulares }\end{array}$ & +++ & +++ & + & + & $\begin{array}{l}\text { parénquima } \\
\text { radial y } \\
\text { peridermis +++ }\end{array}$ \\
\hline \multicolumn{6}{|c|}{ Ziziphus } \\
\hline $\begin{array}{l}\text { Parénquima } \\
\text { axial y radial } \\
\text { córtex }\end{array}$ & lila ++ & & \begin{tabular}{|l} 
fuste ++ \\
ramas+++
\end{tabular} & & \\
\hline $\begin{array}{l}\text { Fibras y } \\
\text { esclereidas }\end{array}$ & turquesa +++ & $\begin{array}{l}\text { fuste +++ } \\
\text { ramas ++ }\end{array}$ & & & \\
\hline $\begin{array}{l}\text { Contenidos } \\
\text { celulares }\end{array}$ & turquesa +++ & $\begin{array}{l}\text { fuste }+++ \\
\text { ramas }++\end{array}$ & & ramas + & fuste ++ \\
\hline
\end{tabular}


1. Cercidium plurifoliolatum (Fig. 1A, 3D-E y $3 K)$.

Anatomía. El floema secundario de esta especie está formado por radios homogéneos que se ensanchan como abanicos angostos que se unen para formar una banda tangencial, son homogéneos y presentan drusas. Continúan en una banda tangencial de esclereidas isodiamétricas con cristales. La peridermis está formada por una capa interna de células suberizadas y una externa de células semejantes a colénquima. El parénquima axial se arregla en bandas delgadas tangenciales. Algunas células del parénquima axial presentan cristales; el resto presenta depósitos de color ámbar. Los elementos cribosos se observan difusos.

\section{Histoquímica.}

Azul de toluidina. Muestra las paredes del parénquima axial de la rama teñidas de lila mientras que las del fuste verde turquesa. Esto se comporta así hasta el punto en que se conecta este tipo de parénquima con la banda tangencial de esclereidas. La banda de esclereidas, al igual que las fibras, presentó una reacción intensa a la lignina. Las fibras se tiñeron de turquesa.

Sudán III. Los depósitos del parénquima axial reaccionaron medianamente, las paredes celulares de la capa externa de la peridermis reaccionaron con un color intenso.

Zinc Cloro lodo (ZnCll). Resalta la presencia de muy pocos depósitos violáceos, lo que indica presencia de pectinas.

Vainillina. Se observaron depósitos de color castaño oscuro en las células de la peridermis y del parénquima axial, indicando presencia de polifenoles. Con esta tinción se define muy bien la ubicación de estos depósitos.
Ácido tánico-Cloruro férrico. Las paredes celulares del parénquima radial y axial, algunos de sus contenidos celulares y las paredes primarias de las fibras, se tiñeron intensamente de negro.

2. Ipomea pauciflora (Fig. 1B, 3F, 3H-J).

Anatomía. El floema secundario de esta especie está formado por radios homogéneos que, muy cerca del cambium vascular, se dilatan para formar una banda ancha tangencial, la cual incluye paquetes de fibras muy cortas y de paredes delgadas. No se desarrolla peridermis y en cambio subsiste un córtex primario que presenta drusas y una epidermis pluriestratificada que presenta contenidos amarillos. Los elementos cribosos se observan difusos.

\section{Histoquímica.}

Azul de toluidina. Las paredes del parénquima axial, radial y de córtex se tiñeron de lila. La banda de esclereidas, al igual que las fibras, presentaron una reacción intensa a la lignina. Los pequeños paquetes de fibras cortas y las esclereidas que se presentan en el córtex se tiñeron de turquesa intenso. Las paredes de la epidermis y la mayoría de sus depósitos se tiñeron de turquesa.

Sudán III. Las células de la epidermis presentaron depósitos de suberina sobre sus paredes, al igual que aquellas que se consideraron de córtex. El resto de las células no presentaron reacción.

ZnCll. Se observaron almidones en el parénquima radial y hacia la periferia estaban prácticamente ausentes.

Vainillina. Se observaron depósitos de color castaño oscuro en las células de todo el parénquima así como en las últimas capas del córtex, indicando presencia de polifenoles.

Ácido tánico-Cloruro férrico. Las paredes celulares del parénquima radial y axial 
reaccionaron con un color intenso. En el parénquima axial se encontraron algunos depósitos con tonos de muy grises hasta negro. Resalta la mediana tinción de las paredes primarias de las fibras y de las últimas células del córtex.

3. Jatropha andrieuxii (Fig. 1C, 2L, 3A-C y $3 G)$.

Anatomía. El floema secundario de esta especie está formado por radios homogéneos que se ensanchan como abanicos muy largos que se unen para formar una banda tangencial. El parénquima axial forma bandas radiales y presenta depósitos de color castaño amarillo. Tanto las bandas radiales de parénquima axial como los radios, forman una zona muy peculiar que se consideró córtex y está formada por tejido parenquimático, el cual incluye canales conteniendo depósitos rojos (látex rojo) y paquetes formados por 3 ó 4 fibras. Hacia el exterior, el córtex está formado sólo por parénquima con abundantes drusas y fibras. Abajo de una epidermis pluriestratificada se llegan a encontrar varias hileras de colénquima. Hay dos clases de parénquima radial, uno de células isodiamétricas y el otro está formando el radio. Las fibras se encuentran arregladas en pequeñas bandas tangenciales. Los elementos cribosos se observan asociados al parénquima.

\section{Histoquímica.}

Azul de toluidina. Las paredes del parénquima axial y radial reaccionaron tiñéndose de lila, con una baja reacción al turquesa, las fibras se tiñeron de turquesa. Los depósitos hialinos del parénquima no se tiñeron. Algunos contenidos de los canales se tiñeron de color turquesa.

Sudán III. Algunos depósitos de las células del córtex reaccionaron medianamente. Algunos depósitos de los canales presentaron una reacción mediana. Los depósitos hialinos del parénquima no se tiñeron. Las paredes de las células del córtex presentaron depósitos de suberina.

Vainillina. Resalta una reacción mediana de los depósitos de los canales que se tiñeron de turquesa. Otros permanecieron del color original.

ZnCll. Se observaron sólo algunos depósitos de pectinas en las células del parénquima. En parénquima radial expandido se observaron depósitos de pectina.

Ácido tánico-Cloruro férrico. Resaltó el hecho de que muchos de los depósitos de los canales se tiñeron de negro; todas las paredes de las células que componen este tejido (desde el cambium vascular hasta la peridermis) también se tiñeron de negro.

\section{Lysiloma divaricata (Fig. 1D, 2H-L).}

Anatomía. El floema secundario de esta especie está formado por radios homogéneos interrumpidos por bandas tangenciales de parénquima axial, que presenta contenidos de color ámbar, fibras y elementos cribosos. La región no dilatada es ancha y los radios se dilatan abrupta e irregularmente, formando una gran banda tangencial de parénquima que presenta contenidos de color ámbar. Las fibras se encuentran rodeadas de parénquima que contiene cristales romboidales. Hacia fuera de la peridermis se localiza una banda tangencial de esclereidas y otras dos más externas, una de células isodiamétricas con depósitos ámbar y otra de células radialmente comprimidas.

\section{Histoquímica.}

Azul de toluidina. En las ramas, las paredes de las células del parénquima axial y elementos cribosos cercanas al cambium vascular se tiñeron de lila. En general, hubo una rápida tendencia a la lignificación. En el floema más desarro- 
llado se observó más claramente esta tendencia. Los radios presentaron algunos depósitos que se tiñeron de color turquesa. En la peridermis o hacia la peridermis se observaron muchos depósitos polifenólicos de color turquesa.

Sudán III. En los radios, muchos depósitos se tiñeron de color naranja intenso. Esto también sucedió en los extractivos de la peridermis, lo cual indicaba la presencia de gran cantidad de lípidos.

ZnCll. El parénquima axial presentó algunos depósitos de color violáceo.

Vainillina. En el parénquima axial se observaron depósitos de color castaño oscuro, lo cual indicaba la presencia de polifenoles.

Acido tánico-Cloruro férrico. Las paredes del parénquima axial se tiñeron medianamente de gris hacia el cambium vascular. Hubo poca reacción de las paredes del resto de los elementos celulares.

\section{Ziziphus amole (Fig. 1E, 2A-G).}

Anatomía. El floema secundario de esta especie está formado por radios homogéneos, que antes de dilatarse son de $187 \mathrm{~mm}$ de altura y $6 \mathrm{~mm}$ de anchura, después se ensanchan formando bandas tangenciales muy irregulares los cuales casi no presentan depósitos. Hay presencia de esclereidas hacia la peridermis formando una pequeña banda tangencial, estas células incluyen en sus cavidades cristales romboidales. En la zona no dilatada hay presencia de paquetes de fibras rodeadas por parénquima que contiene cristales. El parénquima axial está agrupado en paquetes tangenciales y radiales. $\mathrm{La}$ peridermis está formada por células con muchos depósitos de color ámbar y una última capa de células radialmente aplanadas. Los elementos cribosos se observan difusos.
Histoquímica.

Azul de toluidina. Las paredes del parénquima axial y radial presentaron un color lila cerca del cambium vascular, las ramas jóvenes presentaron esta zona más ancha, incluyendo el córtex; en el fuste la zona teñida fue muy pequeña. En el parénquima axial se observaron depósitos de color turquesa. En el fuste se observó una tendencia a aumentar la intensidad en el color turquesa hacia la peridermis. Las paredes de las esclereidas, al igual que las de las fibras, presentaron una reacción intensa a la lignina.

Sudán III. El parénquima axial presentó una gran cantidad de depósitos anaranjados con coloración de mediana intensidad, indicando depósitos de lípidos. Esta intensidad fue mayor en la corteza del fuste que en las de las ramas.

ZnCll. Sólo algunos contenidos de las células de parénquima radial de las ramas llegaron a teñirse. En el fuste la reacción fue negativa.

Vainillina. Las paredes y depósitos de polifenoles en la corteza de fuste se tiñeron más intensamente que en la corteza de ramas.

Ácido tánico-Cloruro férrico. Se presentó una reacción más intensa ante la presencia de pectatos de calcio de las paredes de las células y de algunos depósitos, en la corteza de ramas que en el fuste.

\section{DISCUSIÓN}

La corteza de los ejemplares estudiados presenta características muy particulares de acuerdo con el arreglo de radios, parénquima axial, fibras y peridermis, que pueden coincidir con algunas de las descripciones propuestas por Furuno (1990), básicamente en cuanto a la forma de abanico de los radios y las pequeñas bandas tangenciales de parénquima axial 
que se van alternando con fibras o elementos cribosos o parénquima con cristales.

En los ejemplares que se estudiaron, los radios del floema, en la zona no colapsada, son homogéneos. En Cercidium y Jatropha resalta su estructura dilatada formando abanicos y en Lysiloma y Ziziphus resalta la interrupción de estos por grupos tangenciales de parénquima axial, fibras y elementos cribosos (Lysiloma) o las masas de esclereidas isodiamétricas en Ziziphus (Furuno, 1990). En las cavidades de las células de parénquima se encuentran cristales o depósitos de color castaño amarillo o ámbar. Resalta para Ipomea la corteza poco desarrollada, en la que todavía se encuentra tejido primario (córtex) y paquetes de fibras de floema primario incluidos.

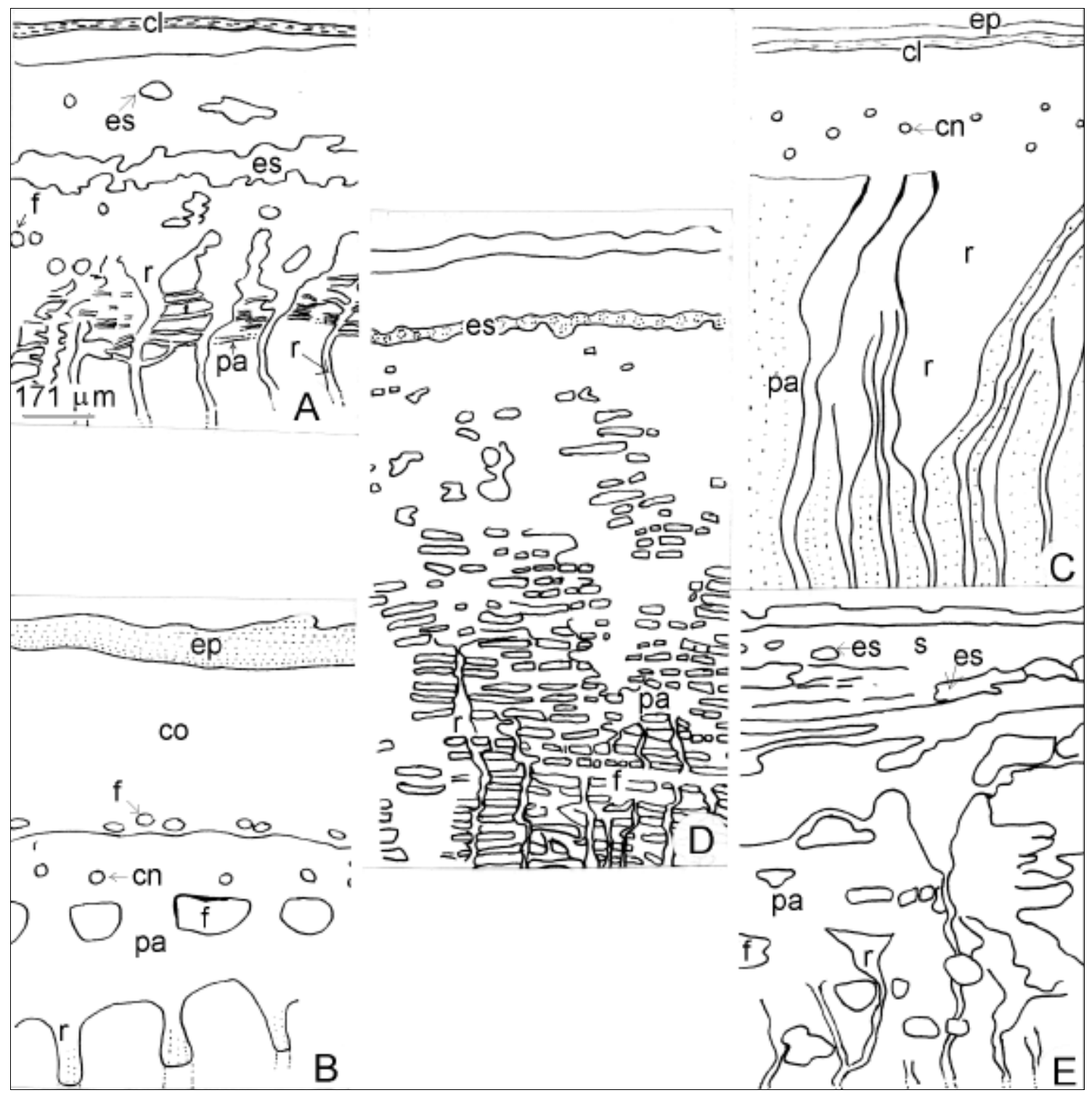

Figura 1. Cortes transversales. A. Cercidium plurifoliolatum, B. Ipomea pauciflora, C. Jatropha andrieuxii, D. Lysiloma divaricata, E. Ziziphus amole.

$\mathrm{f}=$ fibras; $\mathrm{co}=$ córtex; $\mathrm{ep}=$ epidermis; $\mathrm{cl}=$ colénquima, es = esclereidas; $\mathrm{pa}=$ parénquima axial; $\mathrm{r}=$ radios; $\mathrm{cn}=$ canales; $\mathrm{s}=$ células suberizadas 

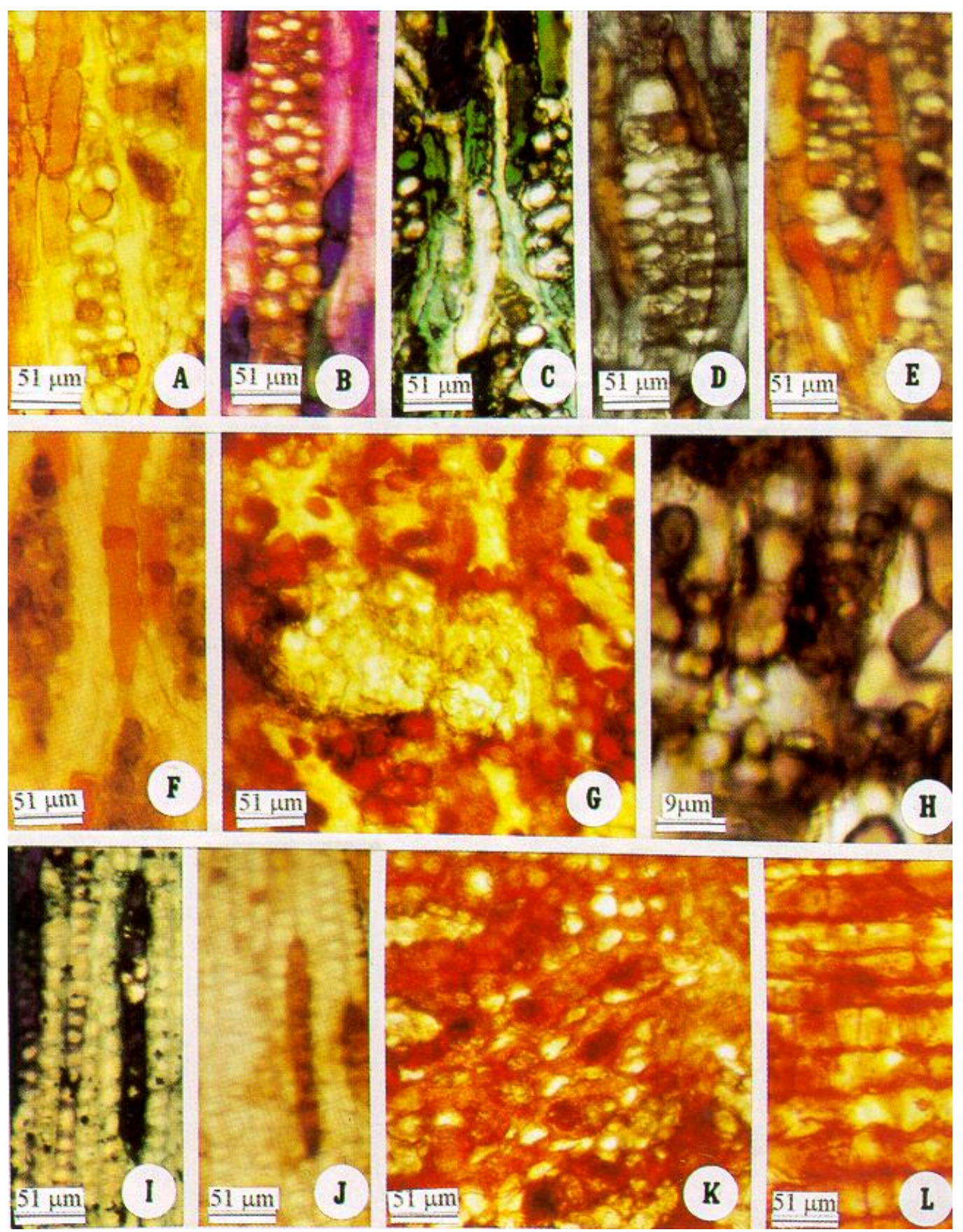

Figura 2. A-G: Ziziphus amole sp. A). Sin tinción (fuste); B). Azul de toluidina (rama); C). Azul de toluidina (fuste); D). Ácido tánico-Cloruro férrico (rama); E). Ácido tánico-Cloruro férrico (fuste); F). ZCII (rama); G). Vainillina H-K: Lysiloma divaricata. H). Ácido tánico-Cloruro férrico; I). Azul de toluidina; J). Sin tinción; K). Vainillina; L: Jatropha. L). Sudán III 

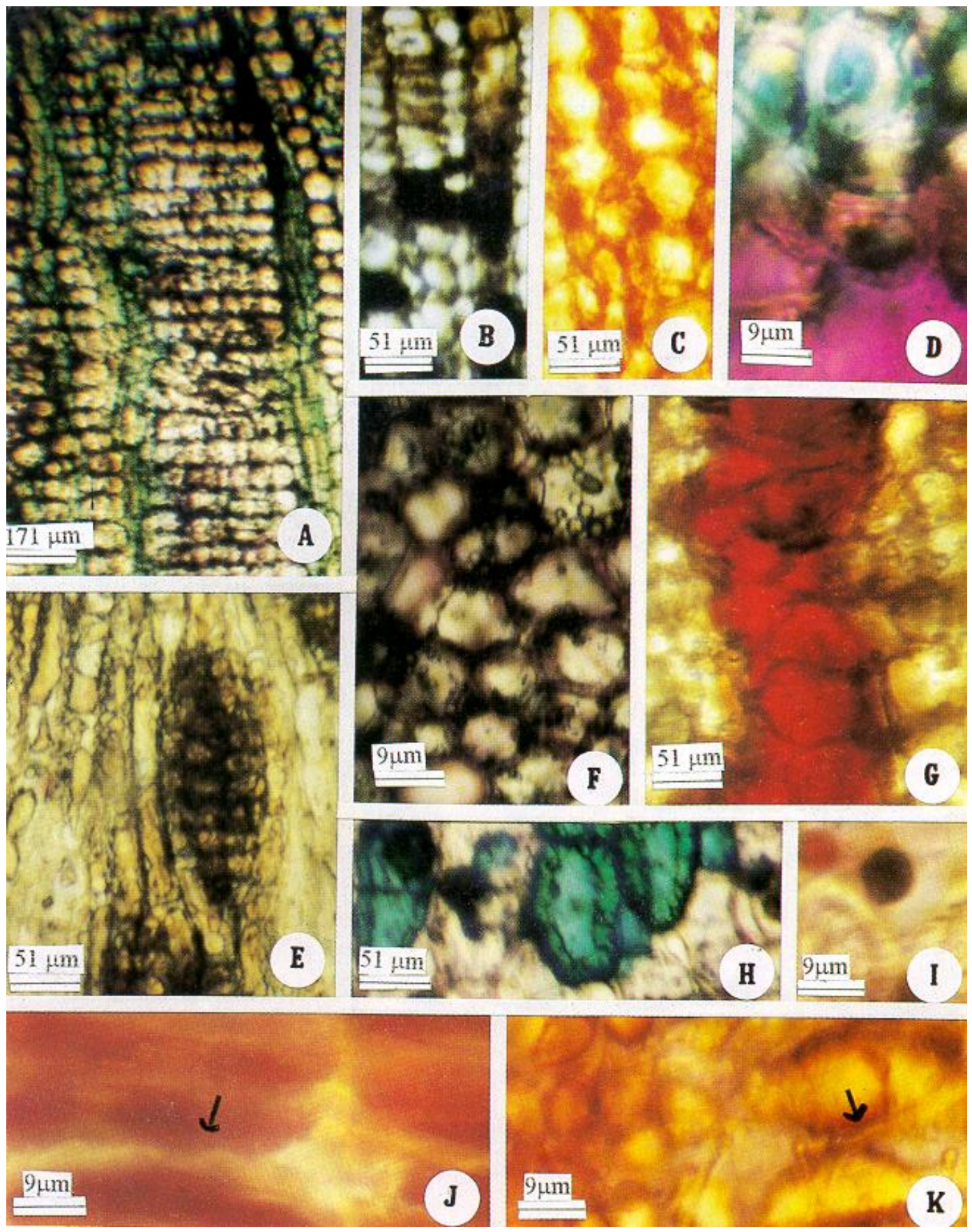

Figura 3. A-C y G: Jatropha andrieuxii. A). Azul de toluidina (3.2x); B). ZCII; C). Sin tinción; G). Sin tinción, canales; D-E y K: Cercidium plurifoliolatum, D). Azul de toluidina; E). Ácido tánico-Cloruro férrico; K). Vainillina; F, H-J: Ipomea pauciflora. F). Ácido tánico-Cloruro férrico; H). Azul de toluidina (esclereida); I). ZnCll depósitos de almidones; J). Vainillina. 
En todos los ejemplares se localizó una banda tangencial de parénquima unida a la parte externa de los radios y posteriormente la peridermis; como lo señala Furuno (1990) existe una convergencia de los radios hacia bandas tangenciales más externas, que en el caso de Cercidium y Lysiloma incluye una banda tangencial de esclereidas isodiamétricas.

De acuerdo con la tabla 1, las fibras de Ipomea son las más cortas, anchas y de paredes delgadas mientras que Cercidium presenta las fibras más largas; el resto de los ejemplares presenta paredes gruesas. Ipomea presenta los radios de mayores dimensiones.

En el estudio anatómico de las especies se identificaron dos tipos de cortezas: uno que forma una estructura continua hasta la aparición de la gran banda de parénquima y otro con estructura discontinua que posteriormente se une también a una zona de parénquima tangencial.

En los fustes y ramas de Ziziphus se observó una clara tendencia a la lignificación (Fig. 2B y 2C). En el parénquima axial de todos los ejemplares se observaron paredes sin lignina hasta la formación de la banda tangencial de parénquima, la cual presentaba, ocasionalmente, depósitos de suberina.

El azul de toluidina y la vainillina ayudaron a mostrar que, en general, las cortezas de estos ejemplares contienen derivados de polifenoles en sus cavidades.

Con el Ácido tánico-Cloruro férrico se observó una intensa reacción ante la presencia de pectatos de calcio, formadores importantes de las paredes de todos los elementos celulares confirmando la escasa presencia de almidones en algunas células de parénquima.
Es interesante notar que el látex rojo que presenta Jatropha en sus canales mostró como componentes polifenoles, derivados de pectinas y aceites (Fig. 3G). Los ejemplares que se estudiaron presentan estrategias estructurales de protección que ocurren característicamente en selvas bajas caducifolias. En este sentido, resalta el proceso de lignificación del parénquima y la deposición de polifenoles y aceites en sus cavidades, así como la presencia importante de fibras y esclereidas; además, el grosor de la peridermis con depósitos de suberina y epidermis lignificadas. Esto explica la baja permeabilidad de las cortezas en regiones como la Cuenca del Río Tehuantepec.

\section{CONCLUSIONES}

Existen tendencias discutidas por Furuno (1990) del arreglo del parénquima axial que permite agrupar a nivel microscópico diversas estrategias de defensa anatómica y mecánica. La relación entre la disposición de los tejidos floemáticos con su crecimiento centrífugo, puede estar relacionada con su pérdida o su permanencia en el tallo, esto es, con la formación 0 no de parénquima que se ensancha como abanicos y ya lejos del cambium una consecuente polifenolización. Este interesante mecanismo de ensanchamiento que presentó por ejemplo Ziziphus, sugiere una estrategia de permanencia en el tallo mayor que en algunas especies de leguminosas que actualmente se encuentran en estudio, en las que sus cortezas son más delgadas, lisas y nunca presentan estructuras en abanicos. El conocimiento que ofrecen los estudios histoquímicos también explicará, como es el caso de Jatropha o más explícito Ziziphus parte de la maduración y muerte celular que está directamente relacionada con algunas estrategias de defensa de la planta. 


\section{RECONOCIMIENTOS}

Este trabajo fue financiado por la Universidad Autónoma MetropolitanaIztapalapa. Se agradece al Comisariado Ejidal Señor Tano Arango por el permiso y valioso apoyo en el trabajo de campo, así como a la P. de Biól. Mariana Velázquez Núñez por su apoyo en la colecta.

\section{REFERENCIAS}

Acosta C., S. 1992. La parte alta de la Cuenca del Río Tehuantepec, Oaxaca: flora, comunidades y relaciones fitogeográficas. Tesis de Maestría. Escuela Nacional de Ciencias Biológicas. Instituto Politécnico Nacional. 102 p.

Alfonso, V.A. y H.G. Richter. 1991. Wood and bark anatomy of Buchenavia Eichl. (Combretaceae). IAWA Bulletin n.s. 12(2): 123-141.

Ángeles G. y C. León G. 1997. Bark anatomy of four tropical Vitaceae from Veracruz, Mexico. IAWA Journal 18(3): 215-228.

Archer, R.H. y A.E. van Wyk. 1993. Bark structure and intergeneric relationships of some southern African Cassionoideae (Celastraceae). IAWA Journal 14 (1): 35-53.

Carlquist, S., E.L. Schneider y R.B. Miller. 1994. Wood and bark anatomy of Argemone (Papaveraceae). IAWA Journal 15(3): 247-255.

Esau, K. 1972. Plant Anatomy. Willey. Nueva York.

Fahn, A. 1990. Plant Anatomy. 4a ed. Pergamon Press. Inglaterra. 643 p.

Furuno, T. 1990. Bark structure of deciduous broad-leaved trees grown in the San'in Region, Japan. IAWA Bulletin n.s. 11(3): 239-254.
Jensen, W.A. 1962. Botanical histochemistry. W.H. Freeman. San Francisco. 406 p.

Johansen, D.A. 1940. Plant microtechnique. McGraw Hill Book Co. Nueva York. 208 p.

Jorge, F.T. Quilhó y H. Pereira. 2000. Variability of fibre length in wood and bark in Eucalyptus globosus. IAWA Journal 21(1): 41-48.

Junikka L. 1994. Survey of English macroscopic bark terminology. IAWA Journal 15(1):3-45.

Krishnamurty, K.V. 1988. Methods in plant histochemistry. Bharathidasan University. S. Viswanathan Press. India.

Malan, J.W y A.E. van Wyk. 1993. Bark structure and preferential bark utilisation by the African elephant. IAWA Journal 14 (2): 173-185.

Nunes, E.T. Quilhó y E. Pereira. 1996. Anatomy and chemical composition of Pinus pinaster. IAWA Journal 17(2):141-149.

Potgieter M.J. y A.E. van Wyk. 1994. Bark structure of the southern African Icacinaceae. IAWA Journal 5(2): 161-170.

Quintanar, A., L. Rivera; A. Torre-Blanco y S. Rebollar. 1997. Comparative histochemistry and cell morphology of sapwood and heartwood of Gliricidia sepium (Fabaceae). Revista de Biología Tropical 45: 1005-1011.

Rivera, L.; A. Quintanar y C. De la Paz Pérez O. 1999. Comparación histoquímica de albura y duramen de tres especies de Quercus. Madera y Bosques 5(1): 27-41. 
Trockenbrodt, M. 1990. Survey and discussion of the terminology used in bark anatomy. IAWA Bulletin n.s. 11:141-166.
Trockenbrodt, M. 1994. Quantitative changes of some anatomical characters during bark development in Quercus ruber, Ulmus glabra, Populus tremula and Betula pendula. IAWA Journal 15(4):387-398.»

1 Departamento de Biología, Universidad Autónoma Metropolitana, Av. San Rafael Atlixco No. 186. 09340. México, D.F. México. aqi@xanum.uam.mx.

2 Herbario, CIIDIR-IPN, Unidad Oaxaca.

3 Laboratorio de Bioquímica. Facultad de Ciencias. UNAM. Cd. Universitaria. Delegación Coyoacán. 04510 México, D.F. México.

Manuscrito recibido el 18 de octubre de 2000

Aceptado el 2 de mayo de 2001

Este documento se debe citar como:

Paredes, C.; A. Quintanar; S. Acosta; G. Orozco; C. De la Paz Pérez O y A. Torre-Blanco. 2001. Histoquímica de la corteza de cinco angiospermas de una selva baja de Oaxaca. Madera y Bosques 7(2):49-61. 